\title{
Efficiency Analysis of the Turbine using Calorific Value Parameters for a 10 Megawatt Gas Turbine
}

\author{
Rex K.C. Amadi ${ }^{1,}{ }^{*} \mathbb{D}$, David Charles ${ }^{1}$
}

${ }^{1}$ Department of Mechanical Engineering, Rivers State University, Nkpolu- Oroworukwo, Port Harcourt, Nigeria
${ }^{*}$ Corresponding author email: amadikemkom@gmail.com

DOI: https://doi.org/10.34256/irjmt2147

Received: 14-06-2021, Revised: 06-07-2021, Accepted: 08-07-2021, Published: 08-07-2021

Abstract: This research is based on the analyzed thermodynamics of a gas turbine energy plant. It considered the differing operating states, i.e. the ambient temperature, the compressor outlet temperature, pressure ratio, etc. and their affective modes on thermal efficiency, turbine work, compressor work, etc. which were derived and analyzed. The Gross (higher) calorific values at constant pressure $\left(\Delta h_{(i \mathrm{iq})}\right)$ heat of combustion in a flow process from state 1 to state 2 was considered and used to analyze our thermal efficiency. Ambient temperature cum air/ fuel ratio affected the turbine work, compressor work and system efficiency. In addition, the thermal efficiency nd power decreases linearly with increase of the ambient temperature. However, the efficiency analyzed when the calorific parameters were considered was higher than the efficiency when the basic thermodynamic theories (first and second law principles) were used. The first ranges between $31 \%$ to 33 , while the second ranges between $28 \%$ to $32 \%$ under the same ambient temperature conditions.

Keywords: Efficiency, Calorific Parameters, Energy Analysis, Turbine work

\section{Introduction}

With the improvement in industrialization and people, there has been an extending interest for electrical energy in Nigeria. Power age in Nigeria is transcendently from three hydro-electric power stations, steam and gas warm stations. An enormous bit of these workplaces are being directed by the Nigerian Electricity Regulatory Commission (NERC), an organization guaranteed administration association that co-ordinates all activities of the power region be it creation, transmission, movement, or exhibiting and bargains. The free regulatory office, as given in the Electric Power Sector Reform Act of 2005 was depended with checking and coordinating the Nigerian power industry, with offering licenses to exhibit individuals, and with ensuring consistence with market oversees and working guidelines.

\section{Oyedepo \& Kalinko (2014) [1] did} Thermodynamic examination of a gas turbine power plant exhibited with an evaporative cooler. in their dissemination the show improvement of gas turbine power plants by cooling the blower utilization air with an evaporative cooler is thought of. This assessment investigated the effect of bay air cooling structure on the introduction of a current gas turbine power plant in
Nigeria. The results show that for each $5^{\circ} \mathrm{C}$ decay of delta air temperature, net yield power increases around $5-10 \%$ and warm usefulness increases around $2-5 \%$. It is shown that the proportion of this development is higher when the squeezing factor extent is high and the turbine channel temperature is low. The results of this assessment shows that the retrofitting of the current gas turbine plant with channel air cooling structure gives a predominant system execution and may wind up being an engaging endeavor opportunity to the Nigerian government and accomplices of the plant.

Kotowicz et.al., (2016) [2], made on the system out of the gas turbine convenience evaluation. An evaluation thinking for isentropic effectiveness of a blower and turbine in a gas turbine establishment reliant upon polytropic sufficiency qualities was introduced. A gas turbine model was outlined into programming projects for power plant age. The evaluation depended upon assessments from iterative models for isentropic ampleness of the blower and the isentropic ability of the base on the turbine inlet temperature.

The isentropic value credits of the blower and the turbine and made through the as of late referred to assessments. The gas turbine improvement for the high blower degrees was the focal basic role for this 
assessment. The got gas electric handiness qualities show that an improvement of pressing variable degree in excess of 50 isn't protected because of the slight expansion in the ability with an essential increase of turbine bay combustor outlet and temperature.

Rahman et.al., (2011) survey thermodynamic execution examination of gas-turbine power plant. The variety of working conditions (pressure proportion, turbine bay and fumes temperature, air to fuel proportion, isentropic blower and turbine proficiency and encompassing temperature) on the exhibition of gas turbine (warm productivity, blower work, power, explicit fuel utilization, heat rate) were researched. The scientific recipe for the particular work and proficiency were inferred and dissected [3].

The outcomes showed that the pressure proportions, encompassing temperature, air to fuel proportion just as the isentropic efficiencies are firmly impacted on the warm productivity. What's more, the warm proficiency and force yield diminishes directly with increment of the encompassing temperature and air to fuel proportion. In any case, the particular fuel utilization and warmth rate increments straightly with expansion in both encompassing temperature and air to fuel proportion. Hence, the thermodynamic boundaries on cycle execution are monetarily possible and gainful for the gas turbine tasks.

The poor performance of these thermal plants has contributed immensely to incessant power outages and economic loss. [4] revealed that only 15 out of the 55 units were available for power generation as at 1994. The 'then Minister of Power and Steel in [5] put the record at 20 out of 55 units (25.6\%) were functional before 1999 and by 2001 the percentage had moved to $43.8 \%$ with the additional 2 units added while 17 units were under rehabilitation.

For greatest economic benefit, the availability of the most efficient and modem plant must be high. Agbauduta (1998), reported that Nigeria's economic losses from unreliable power generation and supply was put at a staggering N66 billion (equivalent to $\$ 0.55$ billion). He identified thy lack of qualified maintenance engineers, non-availability of required spare parts and the instability of the national grid among other factors as being responsible for the poor performance of these power stations [6].

Hart (1992) revealed that the improvement of force age and dissemination in Nigeria didn't at first include a public matrix framework and accordingly, the producing plants were not arranged as for such a framework. The foundation of the framework was made essential on the grounds that an enormous piece of the nation didn't have producing stations situated inside them [7].

\section{Energy Analysis of Power Plants}

Obodeb \& Ugwuoke (2013) did TimeDependent energy examination of a $120 \mathrm{MW}$ steam turbine unit of Sapele Power Plant. The work by and large showed that energy misfortune expanded with expanded activity time. It was seen that disintegration and oldness might be the serious issues and that plant restoration is a possible arrangement [8].

Kwak et al., (2010), checked exergetic and thermo-economic analyses on a 500-MW Power plant running a combined cycle system. In the analysis, they contemplated the protection of mass and energy of every part in the framework [9]. They likewise consider the quantitative equilibrium of exergy and exergetic cost (exergoeconornics) related with every part, and for the framework all in all. In an exergoeconomic model, they addressed the useful construction of the framework to imagine the expense related with the arrangement cycle and the useful connection between parts. Kwak fostered a PC program to decide the creation expenses of force plants using gas or steam turbines, or a blend of the two (cogeneration plant). The prom could likewise be utilized to consider plant qualities, especially thermodynamic execution and framework affectability change. The kind of changes inferred here are in measure and additionally segment plan factors.

Vundela et al. (2010) inspected on energy investigation of nuclear energy stations. They surveyed a thermodynamic examination of a coal based nuclear energy station and gas-based cogeneration power plant as far as energy for the various segments of the force plants in sub-basic reach. They presumed that, the significant energy misfortune was found to happen in condenser. The energy investigation showed that ignition chamber in both steam and gas turbine nuclear energy stations is primary wellspring of irreversibility. The irreversibility in condenser is inconsequential as the bad quality energy is lost in the condenser [10].

Egware and Obanor (2013) investigated energy examination of Omotosho stage 1 gas nuclear energy station. In their examination, they saw that exergy effectiveness diminishes and exergy annihilation productivity increments as surrounding temperature expansions in the plant and its parts [11].

Ahmadi et al., (2011) did Performed Thermodynamic displaying, exergy and exergoeconornic investigation and advancement of a joined cycle power plant. Their examination 
demonstrates wise. The exergy obliteration is attributed to the irreversibility's related with the burning response and the warmth move across huge temperature contrasts between the lighted gases and the functioning liquid. Besides, the exergoeconomic examination recognizes the ignition chamber as having the best expense related with exergy annihilation, everything being equal. It is additionally confirmed that expanding the Gas Turbine Inlet Temperature (GTIT), adequately diminishes the proficiency of the turbine [12].

\section{Materials and Methods}

\section{Calorific Value Analysis}

Ordinarily stated, the calorific value of a fuel is the amount of heat liberated when a kilogram mass of fuel is assuredly burnt (synonymous to heat of combustion). However, it is defined with reference to the state (temperature, pressure and volume).

Four types of calorific values are defined

\section{For non-flow process:}

(i) Higher (Gross) calorific value at constant volume, $\Delta U$ (liq)

This is $\approx \Delta U_{0}$ with the $\mathrm{H}_{2} \mathrm{O}$ in the product in the liquid phase

$-\Delta U_{0}=-\Delta H_{0}+\Delta\left(P V_{0}\right)$

$(\because 4=u+p)$

If the fuel is a gas

$-\Delta U_{0}=-\Delta H_{0}+\Delta\left(R_{0} T_{0}\right)$

(ii) Lower (Net) calorific value at constant volume, $\Delta U$ (vap)

This is $\approx \Delta U_{0}$ with the water of the product in the vapour phase

$-\Delta U_{0}=-\Delta H_{0}+\Delta\left(P V_{0}\right)$

Note:

$\Delta U(v a p)-\Delta U($ Liq $)=\eta H_{2} 0\left(U_{f g}^{\prime}\right)$

$U_{f g}^{\prime}=U_{f g}$ (latent heat of vapourization of water at constant volume at $25^{\circ} \mathrm{C}$ ).
For flow process:

(iii) Higher (Gross) calorific value at constant pressure $\left(\Delta h_{(l i q)}\right)$

This is $\approx-\Delta H_{0}$ with the $\mathrm{H}_{2} \mathrm{O}$ of the product in the liquid phase.

(iv) Lower (Net) calorific value at constant pressure $\left(\Delta h_{(\text {Vap })}\right)$

This is $\approx-\Delta H_{0}$ with the $\mathrm{H}_{2} \mathrm{O}$ of the product in the liquid phase.

Note:

$\Delta h_{(\text {vap })}-\Delta h_{(\text {lip })}=n H_{2} O h_{f g}^{\prime \prime}$

Where $h_{f g}^{\prime}=h_{f g}$ of $\mathrm{H} 2 \mathrm{O}$ at reference temp of $\left(25^{\circ} \mathrm{C}\right)$

\section{Heat of Combustion}

Applying first law of thermodynamics to combustion results in heat of combustion.

Two types of heat of combustion are defined.

(i) Constant volume heat of combustion or internal energy of combustion $\left(\Delta U_{0}\right)$, and

(ii) Constant pressure heat of combustion or enthalpy of combustion $\left(\Delta H_{0}\right)$

(a) Internal energy of (constant volume heat of) combustion is the heat of combustion generated in the none-flow process.

$Q^{-}=U_{p 2}-U_{R 1}$

$$
\begin{aligned}
& \text { State } 1 \\
& \text { State } 0 \\
& \text { (reference) } \\
& \text { State } 2 \\
& \text { Reactants }(\mathrm{R}) \\
& \text { Combustion } \\
& \text { Product (P) } \\
& R\left(P_{1}, V_{1}, T_{1}\right) \\
& R\left(P_{0}, V_{0}, T_{0}\right) P \\
& \left(P_{2}, V_{2}, T_{2}\right) P \\
& T_{1} \underset{\text { some therm additionof heat }}{\longrightarrow} T_{0} \underset{\text { Combustion }}{\longrightarrow} \\
& T_{0} \underset{\text { some therm process cooling }}{\longrightarrow}
\end{aligned}
$$

Some thermal process (addition of heat) some 
The total change of internal energy between state 1 and 2 may be written as:

$U_{P 2}-U_{R 1}=\left(U_{P 2}-U_{P 0}\right)+$

$\left(U_{P 0}-U_{R 0}\right)+\left(U_{R 0}-U_{R 1}\right)$

Where

$U_{R 0}-U_{R 1}=\sum_{R} \eta_{i}\left(\bar{U}_{i 0}-\bar{U}_{i 1}\right)=\sum_{R} m_{i}\left(u_{i 0}-u_{i 1}\right)$

$U_{P 2}-U_{P 0}=\sum_{P} n_{i}\left(\bar{U}_{i 2}-\bar{U}_{i 0}\right)=\sum_{P} m_{i}\left(u_{i 2}-u_{i 0}\right)$

Where $\eta_{i}=$ the amount of substance (mol) of the constituents

$$
\begin{aligned}
& m_{i}=\text { mass of the constituents } \\
& \bar{u}_{i}=\text { Tabulated values of internal energy of }
\end{aligned}
$$
the constituents at the required temp $T_{0}$ or $T_{i}$ per mole.

$$
U_{i}=\quad \text { Internal energy per unit mass }
$$

$U_{P 0}-U_{R 0}=\Delta U_{0}=$ Heat generated in combustion called the internal energy of combustion at $\mathrm{T}_{0}$

The reference $T_{0}$ is usually taken as $25^{\circ} \mathrm{C}$ (298K)

For gaseous reactants and products

$$
\begin{aligned}
U_{P 2}-U_{P 0}= & \left(T_{2}-T_{0}\right) \sum_{P} m_{i} C v_{i}\left(T_{2}-T_{0}\right)= \\
& \sum_{P} m_{i} C v_{i}\left(T_{0}-T_{1}\right)= \\
U_{R 0}-U_{R 1}= & \left(T_{0}-T_{1}\right) \sum_{R} m_{i} C v_{i}
\end{aligned}
$$

Where $\mathrm{mi}$ is the mass of the various constituents and $\mathrm{C}_{\mathrm{vi}}$ is the mean specific heat at constant volume for the appropriate temperature ranges $T_{0}$ to $T_{2}$ and $T_{0}$ to $T_{1}$.
(b) Enthalpy of (constant pressure heat of) combustion is the heat of combustion generated in a flow process.

Considering combustion in a flow process from state 1 to state 2 , from

$$
Q-W=H_{P 2}-H_{R 1}
$$

Total change of enthalpy between states 1 and 2 may be written as:

$$
H_{P 2}-H_{R 1}=\left(H_{P 2}-H_{P 0}\right)+\left(H_{P 0}-H_{R 0}\right)+\left(H_{R 0}-H_{R 1}\right)
$$

Where $H_{R 0}-H_{R 1}=\sum_{R} \eta_{i}\left(\bar{h}_{i 0}-\bar{h}_{i 1}\right)=\sum_{R} m_{i}\left(h_{i 0}-h_{i 1}\right)$

$$
H_{P 2}-H_{P 0}=\sum_{P} n_{i}\left(\bar{h}_{i 2}-\bar{h}_{i 0}\right)=\sum_{P} m_{i}\left(h_{i 2}-h_{i 0}\right)
$$

Where $\bar{h}=$ tabulated enthalpy value per mole

$h=$ enthalpy per unit mass

$$
H_{P 0}-H_{R 0}=\Delta H_{0}
$$

$=$ heat generated during combustion and it is called the enthalpy of combustion or constant pressure heat of combustion at $T_{0}$

For gaseous reactants and products

$H_{P 2}-H_{P 0}=\sum_{P} m_{i} C p_{i}\left(T_{2}-T_{0}\right)=\left(T_{2}-T_{0}\right) \sum_{p} m_{i} C p_{i}$

$H_{R 0}-H_{R 1}=$

$\sum_{R} m_{i} C p_{i}\left(T_{0}-T_{1}\right)=$

$\left(T_{0}-T_{1}\right) \sum_{R} m_{i} C p_{i}$

Where $\mathrm{CP}_{\mathrm{i}}=$ mean specific heat at constant pressure for the ranges $T_{0}$ to $T_{2} ; T_{0}$ to $T_{1}$

$\Delta H_{0}$ and $\Delta H_{0}$ are measured when both the combustion reactants and products are both at $\mathrm{T}_{0}$.

Value of $\Delta U_{0}$ and $\Delta H_{0}$ are usually quoted for $25^{\circ} \mathrm{C}$ and for $1 \mathrm{~kg}$ or $1 \mathrm{~mol}$.

Also values of $\Delta U_{0}$ and $\Delta H_{0}$ are quoted with the phases of reactants and products specified (solid, liquid, gas) e.g.

$$
\begin{gathered}
\mathrm{CH}_{4}+2 \mathrm{O}_{2} \rightarrow \mathrm{CO}_{2}+2 \mathrm{H}_{2} \mathrm{O} \text { (liquid) } \\
\text { Or }
\end{gathered}
$$

$\mathrm{CH}_{4}+2 \mathrm{O}_{2} \rightarrow \mathrm{CO}_{2}+2 \mathrm{H}_{2} \mathrm{O}_{\text {(vap) }}$

Other reactants and products $\mathrm{CH}_{4}, \mathrm{O}_{2}, \mathrm{CO}_{2}$ are known to be gases.

If any constituent undergoes a change of phase the appropriate latent heat of vaporization $\left(\mathrm{h}_{\mathrm{fg}}\right)$ must be included. 
The difference between the $\Delta H_{0}$ for a fuel in the liquid phase and $\Delta H_{0}$ for same fuel in the gaseous phase is the latent heat of vaporization.

Generally for gaseous fuels

$$
\begin{aligned}
& \Delta H_{0}=\Delta U_{0}+R_{0} T_{0}(n P-n R) \\
& (\because h=u+p v=u+n R T)
\end{aligned}
$$

Where $R_{0}=$ Universal gas constant

$=\mathrm{RM}$; where $\mathrm{M}=$ molar mass; $\mathrm{R}=$ specific gas constant

$\mathrm{NP}$ and $\mathrm{nR}$ are number of moles of products and reactants respectively.

Property tables for gases are used to calculate the terms in the equations that relate enthalpy changes.

The mean specific heat for a range of temperature $t_{1}$ to

$t_{2}$ is equal to that for the average temperature $\frac{t_{1}+t_{2}}{2}$

only if the specific heat-temperature relation is linear, otherwise accurate calculation should be done with values from the gas tables.

Hence, e.g.

$H_{P 1}-H_{P 0}=\sum_{p} n_{i}\left(h_{t 1}-h_{t 0}\right)$

Where $h_{t 1}$ and $h_{t 0}$ are obtained from gas tables at temperature $t_{1}$ and to respectively and $n_{i}=$ mole of each constituent.

\section{Enthalpy of Formation}

Enthalpy of formation of a compound is the heat-transfer obtained as change in enthalpy between the product and reactants when the enthalpy of the all the elements (reactants) are made zero at standard condition of $25^{\circ} \mathrm{C}$ and 1 bar.

E.g. $\mathrm{CO}_{2}$ is formed at $25^{\circ} \mathrm{C}$ and 1 bar from complete combustion of $\mathrm{C}$ in $\mathrm{O}_{2}$

$$
\mathrm{C}+\mathrm{O}_{2} \rightarrow \mathrm{CO}_{2}+(-393,522 \mathrm{kj})
$$

Applying $1^{\text {st }}$ law of thermodynamics

$$
Q=H_{P}-H_{R}=\sum_{P} n i h i-\sum_{R} n i h i
$$

If the enthalpy of $\mathrm{O}_{2}$ and $\mathrm{C}$ (reactants) = zero (being elements in their normal states) at $25^{\circ} \mathrm{C}$ and 1 bar.
Then

$$
Q=H_{P}=\sum_{p} n i h i=-393,522 \mathrm{kj} / \mathrm{mol}
$$

$=$ the enthalpy of formation of $\mathrm{CO} 2$ at $250 \mathrm{C}$ and 1 bar, denoted by $\mathrm{h}_{\mathrm{f}}$

Thus $\left(\mathrm{h}_{\mathrm{f}}\right) \mathrm{CO}_{2}=393522 \mathrm{kj} / \mathrm{mol}$

The enthalpy of $\mathrm{CO}_{2}$ at any other state (any other temperature and pressure) relative to $25^{\circ} \mathrm{C}$ and 1 bar is given by

$h_{T, P}=h_{f}^{0} \Delta h=h_{f}^{0}+\left(h_{T}-h_{298}\right)$

$=\mathrm{h}$ at any other pressure and temperature.

$$
Q=H_{P}-H_{R}=\sum_{P} n_{i}\left(h_{f}^{0}+\Delta h\right)_{i}-\sum_{R} n_{i}\left(h_{f}^{0}+\Delta h\right)_{i}
$$

Where $\Delta h=$ change in enthalpy between $25^{\circ} \mathrm{C}(298 \mathrm{~K})$, 1 bar and the required temperature and pressure $=h_{T}-h_{298}$

$h_{T, P}=h_{f}^{0}+\left(h_{T}-h_{298}\right)$

\section{Results and Discussion}

Following the procedurals and equations adopted, the outcome of the performance improvement of thermal power systems through energy efficiency analysis was presented. The plant energy efficiency of the gas turbine components has been evaluated.

\section{Presentation of Input Data}

Appropriate assumptions have been made for the power plant and stated in table 1 such that the results obtained will closely approximate actual data from the gas turbines.

Table 1. Energy Performance Analysis

\begin{tabular}{|l|l|l|}
\hline $\mathbf{S} / \mathbf{N}$ & \multicolumn{1}{|c|}{ Parameters } & Dave Energy \\
\hline 1. & $\begin{array}{l}\mathrm{CH}_{4} \quad \text { calorific parameter } \\
(\mathrm{kJ} / \mathrm{kg})\end{array}$ & 55208 \\
\hline 2. & Net power of turbine & 10650 \\
\hline 3. & Gas flow rate $(\mathrm{kg} / \mathrm{hr})$ & 170 \\
\hline 4. & Air fuel ratio & $63: 1$ \\
\hline 5. & Pressure ratio & $15: 1$ \\
\hline 6. & Turbine efficiency & 85 \\
\hline 7. & Compressor efficiency & 80 \\
\hline 8. & Ambient temp (TI) & 30 \\
\hline 9. & Thermal efficiency & 31.5 \\
\hline
\end{tabular}

Table 1 presents the results of the energy analysis of the gas turbine. The result shows the energy efficiency 
using the calorific parameters with ambient temperature at $30^{\circ} \mathrm{C}$. The value for the calorific value was derived using the parameters in table 4.2 and equation 13 to 14 we were able to derive the calorific value for methane.

Table 2. Energy Performance Analysis

\begin{tabular}{|c|l|l|}
\hline $\mathbf{S} / \mathbf{N}$ & Parameters & $\begin{array}{c}\text { Specific heat capacity at } \\
500 k \text { (cp } \mathbf{~ J / k g ~ K )}\end{array}$ \\
\hline 1 & $\mathrm{CH}_{4}$ & 2.293 \\
\hline 2 & $\mathrm{O}_{2}$ & 0.972 \\
\hline 3 & $\mathrm{CO}_{2}$ & 1.014 \\
\hline 4 & $\mathrm{H}_{2} \mathrm{O}_{(\mathrm{g})}$ & 1.954 \\
\hline
\end{tabular}

The data in table 2 was derived from standard table of specific heat capacity. The parameters are the relevant specific heat capacity $(\mathrm{cp})$ at $500 \mathrm{~K}$. These parameters were used in deriving the calorific value of methane $\mathrm{CH} 4$. Using equation 13to 14 in the previous chapter we were able to derive the calorific value for methane.

Table 3. Effect of Compressor Outlet Temperature on Turbine load considmering its Ambient Temperature

\begin{tabular}{|c|c|c|}
\hline $\mathbf{S} / \mathbf{N}$ & $\begin{array}{c}\text { Ambient } \\
\text { temperature }\left({ }^{\circ} \mathbf{C}\right)\end{array}$ & $\begin{array}{c}\text { Turbine load } \\
\mathbf{( k W})\end{array}$ \\
\hline 1 & 20 & 10752.57 \\
\hline 2 & 22 & 10725.04 \\
\hline 3 & 24 & 10697.51 \\
\hline 4 & 25 & 10683.74 \\
\hline 5 & 27 & 10656.2 \\
\hline 6 & 30 & 10614.9 \\
\hline 7 & 35 & 10546.07 \\
\hline
\end{tabular}

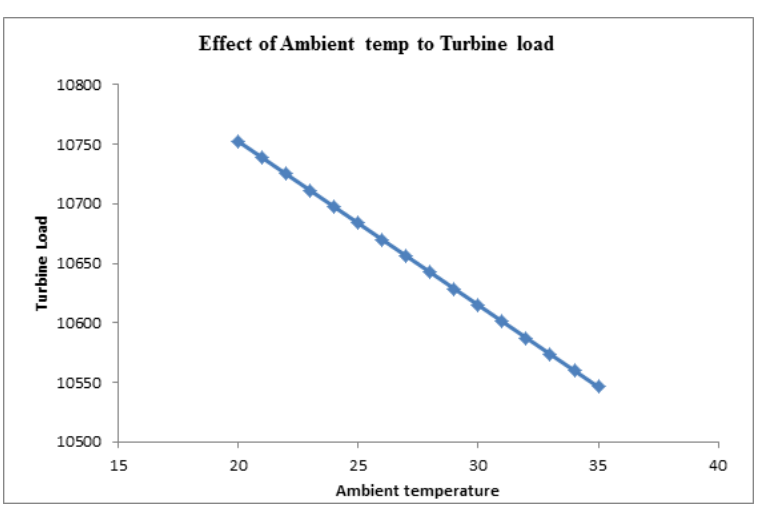

Figure 1. Effect of ambient temp to turbine load

From table 3 and figure 1 , the results show a significant decrease in turbine load as inlet temperature increases just as its efficiency is affected when ambient temperature increases. This is due to the density of air reducing at increase in ambient temperature.

Table 4. Comparison between efficiencies of Thermal efficiency principles with that of calorific efficiency with respect to their ambient temperature

\begin{tabular}{|c|l|l|l|}
\hline $\mathbf{S} / \mathbf{N}$ & $\begin{array}{l}\text { Ambient } \\
\text { temperat } \\
\text { ure }\left({ }^{\circ} \mathbf{C}\right)\end{array}$ & $\begin{array}{l}\text { Calorific } \\
\text { efficiency }\end{array}$ & $\begin{array}{l}\text { Thermal } \\
\text { efficiency }\end{array}$ \\
\hline 1 & 20 & 0.319317 & 0.317526 \\
\hline 2 & 22 & 0.318569 & 0.313509 \\
\hline 3 & 24 & 0.317821 & 0.309491 \\
\hline 4 & 25 & 0.317447 & 0.307482 \\
\hline 5 & 27 & 0.316699 & 0.303465 \\
\hline 6 & 30 & 0.315577 & 0.297439 \\
\hline 7 & 35 & 0.313706 & 0.287395 \\
\hline
\end{tabular}

The table 4 shows us the varying results of both thermal efficiency and calorific efficiency at different inlet temperatures. Although its efficiencies are decreasing with increase in inlet temperature but their values differ at the same temperature value. The calorific efficiency values are higher than the thermal efficiency values.

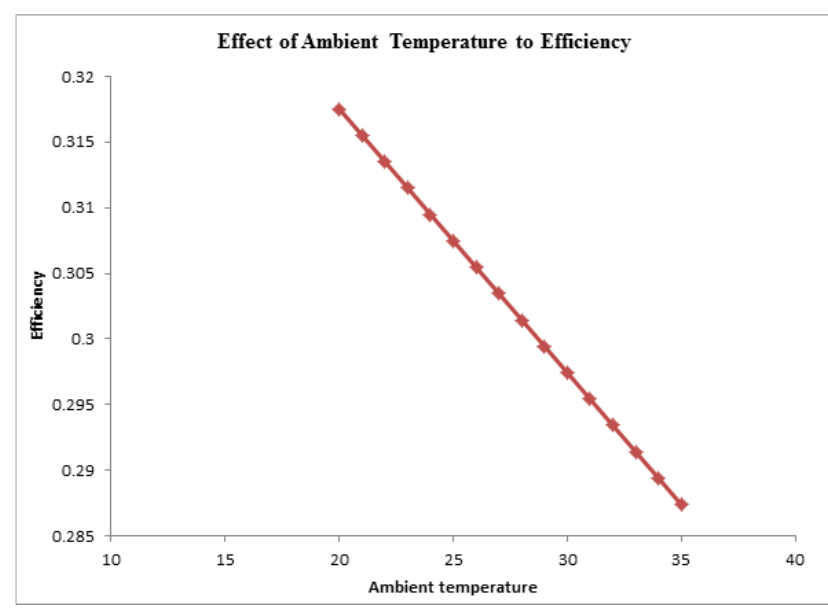

Figure 2. Effect of ambient temperature to efficiency

The efficiency of the gas turbine plant depends on the temperature of the inlet air. At high ambient temperatures there's drop in turbine efficiency. Fig 4 and table 4 considering just the parameters under the thermal efficiency shows the results of the thermal efficiency of the gas turbine with respect to ambient temperature which is one of the objectives of this project. We could see the linear decrease in efficiency 
as the ambient temperature increases from $20^{\circ} \mathrm{C}$ to $35^{\circ} \mathrm{C}$. There's about $3 \%$ to $4 \%$ loss in thermal efficiency.

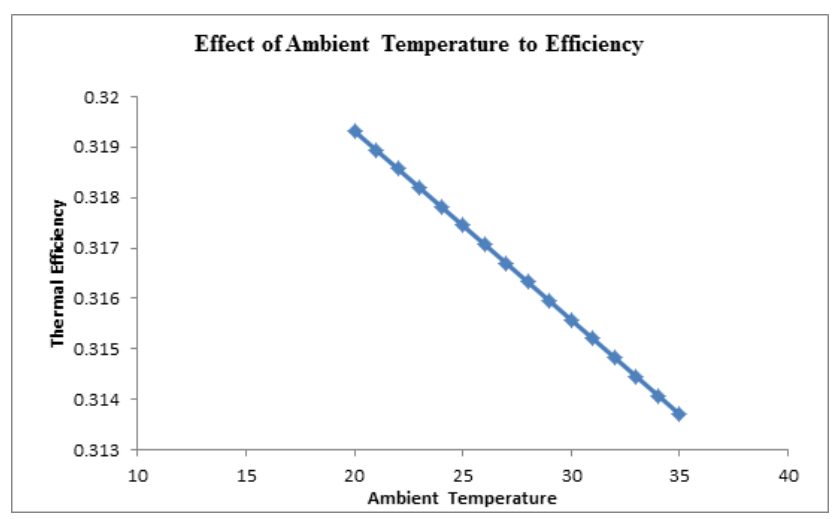

Figure 3. Effect of ambient temperature to efficiency

Increased ambient temperature lowers the density of the inlet air, thus reducing the mass flow through the turbine and therefore reduces the efficiency. At constant speed, where the volume flow remains approximately constant, the mass flow will increase with decreasing temperature and will increase with increasing temperature. Fig 5 and table 4 considering just the parameters under the calorific efficiency shows the results of the efficiency of the gas turbine with respect to its temperature. There's as well a decrease in efficiency of about $2 \%$ as the ambient temperature rises.

The figures 2 and 3 compare the efficiency of the turbine. The comparison is between efficiencies when calorific parameters are considered and when they are not at different ambient temperatures. We could see from the above figures that when the calorific parameters are used the efficiency ranges between $31 \%$ and $33 \%$, while when calorific parameters are not considered the efficiency ranges between $28 \%$ to $32 \%$. Hence, at higher ambient temperatures the efficiencies are lower when the nature of heat of combustion is not put into consideration. This could also be due to some forms of energy losses in the different components.

\section{Comparison with Work of Past Researchers}

In the work of Rahman and Thamir (2011) carried out analysis of the effect of ambient temperature, compression ratio and air to fuel ratio, etc. on the thermal efficiency. The present research having analyzed various operational conditions of Dave Energy Power Plant exposed the shortcomings of energy analysis when the Gross Ethalpy of (Constant pressure heat of) combustion is not put into consideration.

However, both analyses are relevant in the performance analysis of a power plant.
While in the work of Kotowicz (2016) carried out analysis on the methodology of the gas turbine efficiency calculation even when the Gross efficiency is considered. The efficiency of the turbine was around $22 \%$ while this research ranges from $31 \%$. However, both analysis are still relevant in the performance analysis of gas turbine.

\section{Conclusion}

The result from the modeling of the influence of parameter showed that ambient temperature, air fuel ratio and turbine outlet temperature effect on performance of gas turbine power plant. The results were summarized as follows:

(i) The thermal efficiency and power output decreases linearly with increased of ambient temperature as well as the air to fuel ratio.

(ii) The variation of thermal efficiency at higher compression ratio, turbine outlet temperature and ambient temperature are very important.

(iii) The nature of the heat of combustion in the turbine with its effect on the turbine efficiency is important and necessary to consider while analyzing.

(iv) The thermal efficiency and power output decreases linearly with increase in ambient temperature.

(v) The peak efficiency and power occur at lower ambient temperature.

\section{References}

[1] S.O. Oyedepo, O. Kalinko, Thermodynamic Analysis of a Gas Turbine Power Plant Modeled with an Evaporative Cooler. International Journal of Thermodynamics. 17 (2014) 14-20. [DOI]

[2] J. Kotowicz, M. Job, K. Nawrat, J. Medrich, The methodology of gas turbine efficiency calculation, Archives of Thermodynamics 37 (2016) 19-35. [DOI]

[3] M.M. Rahman, T.K. Ibrahim, A.N. Abdalla, Thermodynamic performance analyis of gasturbine power-plant, International Journal of the Physical Sciences, 6 (2011) 3539-3550. [DOI]

[4] E.I.K. Sule, C.M Anyanwu, An Appraisal of Electricity Supply in Nigeria and the Privatization Option, Research Department in National Development, 1 (1994) 6-16.

[5] The Punch Newspaper, (May 7th, 2001). 
Operational Gas Turbine Analysis. P13.

[6] K.E. Agbauduta, A Study of Sections Interactions Effects on thermodynamic Efficiencies of a Thermal Power Plant, British Journal of Applied Science and Technology, 3 (1998) 1201-1214. [DOI]

[7] H.I. Hart, Gas Turbine operation experience in the Niger Delta area of Nigeria, official Journal of the Nigeria Engineer, 27 (1992) 198-211.

[8] C.G. Obodeh, K. Ugwuoke, Exergy Analysis; Principles and Practice, Journal of Engineering of Gas Turbines and Power, 1 (2013) 1-12.

[9] K. Wark, D.E. Richards, (1998) Thermodynamics, 6th Edition, McGraw-Hill Company, New York.

[10] S.R. Vundela, C.K. Subhash, K.T. Sudhir, L.P. Naraya, An Approach to Analyze Energy and Exergy Analysis of Thermal Power Plane: A Review, Smart Grid and Renewable Energy, International Journal of Science and Research, 1 (2010) 143-152. [DOI]

[11] H.O. Egware, A.I. Obanor, Energy Analysis of Omotosho Phase 1 Gas Thermal Power Plant, International Journal of Engineering and Technology Sciences (IJETS), 1 (2013) 206217.

[12] P. Ahmadi, I. Dincer, M. Rosen, Exergy, Exergoeconomic and Environmental Analyses and Evolutionary Algorithm based Multiobjective Optimization of Combined Cycle Power Plant, Energy, 36 (2011) 5886-5898. [DOI]

\section{Funding}

No funding was received for conducting this study.

\section{Conflict of interest}

The authors have no conflicts of interest to declare that they are relevant to the content of this article.

\section{About the License}

(C) The author(s) 2021. The text of this article is open access and licensed under a Creative Commons Attribution 4.0 International License 